\title{
TABULA GRATULATORIA A JOSÉ LUIS DELGADO
}

Soy Ana Belén Cerezo Aparicio, antigua alumna de la III edición del Curso Extraordinario de Protocolo, Comunicación e Imagen Corporativa de la Universidad de Salamanca.Te agradezco tu iniciativa. He intentado sintetizar mi recuerdo a José Luis, pero no me ha sido posible. Considerad lo que estiméis.

Conocí a José Luis Delgado en la III edición del Curso Extraordinario de Protocolo, Comunicación e Imagen Corporativa organizado por la Universidad de Salamanca y dirigido muy sabiamente, con profesionalidad y rigor por él mismo.Desde el momento en el que intercambié las primeras palabras con José Luis, me pareció una persona afable y cercana, a la vez que serio. Debo decir que tuvo "algo", eso que no se explica con palabras, que nos toca y parece magia. Con su mano izquierda, su intenso amor por el Protocolo nos enseñó a apreciar cada detalle y hacer nuestra una profesión independientemente de que nos fuéramos a dedicar a ella o no. Le guardaba un gran respeto y cariño, de hecho, fue de quien aprendí la frase de Talleyrand "Solo los necios se ríen del Protocolo, simplifica la vida". Además de su rigor y profesionalidad en sus clases, en las que disfrutaba, no había más que verle, ponía de manifiesto su gran humildad al presentarnos a los demás ponentes del curso, les apreciaba y reconocía sus trabajos sinceramente y predisponía a la escucha atenta.Permanecimos en contacto por lo cercano que era, porque deseaba crear interacciones futuras y porque era una persona interesantísima, con un gran bagaje cultural, la "formación humanística" que nos refería debía poseer un profesional del Protocolo.Gran persona, altruísta (siempre tenía tiempo que no le sobraba para dedicárnoslo), sensible, sabía escuchar, excelente comunicador, entusiasta hasta en las más bravas lecciones de la vida, único, profesional, riguroso, sutil...Doy gracias al Cielo por haberle conocido. Fue un placer del que me quedan ahora sus enseñanzas vitales y profesionales.Un fuerte abrazo y gracias por todo dondequiera que estés, José Luis, allá en la Luz quien ve y que ya eres.Discúlpame si no supe estar a la altura de lo que esperabas de mí.

Con mi más sincero respeto y admiración por un gran profesor y mejor persona, siempre presente en nuestra memoria y afecto.

Cristina Allott

Enérgico en su conversación. Consiguió definir claramente lo que en los últimos años se ha venido a llamar "marca personal" que no es más que una forma de ser que te consigue diferenciar del resto y te hace inconfundible.

Un abrazo,

$-$

Margarita Murillo

Directora Galicia Protocolo

Sensible, pasional, risueño y vehemente, eras querido José Luis una persona muy especial, un amigo de verdad, leal, fiel y honesto.

Perseverante y tenaz, jamás te rendiste. Orgullosa afirmo que plantaste batalla hasta el final. Un digno luchador fiel a tus principios y valores.

Añoraré con pesar las largas conversaciones que manteníamos sobre la vida, el futuro, los sueños, los proyectos, las injusticias, las oportunidades, y tantos y tantos temas que ya no volveremos a tratar. 
Te confesaré que mi corazón guarda un profundo dolor. No sospeché que partirías tan pronto. Planeaba acercarme a visitarte... a despedirme. No me dio tiempo a hacerlo. Quería consolarte, abrazarte, decirte que eras un ser maravilloso y un amigo del alma. Que ha sido un placer y un honor conocerte y tratarte y que siempre, estés donde estés, te recordaré. Querido amigo, has dejado de sufrir.

Mar Castro

Amiga de José Luis

Profesora en los cursos de postgrado en protocolo que dirigía en la USAL

Adiós a un maestro del protocolo. José Luis Delgado, querido amigo

José Luis Delgado fue un hombre de vasta cultura, polifacético, que supo combinar su formación en periodismo y en protocolo con sus innatas dotes comunicativas para completar una exitosa trayectoria que hoy todo el mundo le reconoce. José Luis fue en vida todo lo que quería ser: un gran maestro del protocolo y la comunicación, un magnífico docente y, sobre todo, un excepcional ser humano que ha dejado una huella profunda en todos los que le conocimos y tratamos. Carismático, cortés, amable, elegante, justo, sabio, generoso, entregado, trabajador incansable... me faltan calificativos para dibujar el retrato de un hombre que, ante todo, fue honesto e hizo de la ética y el respeto su bandera. "Saber ser y saber estar" era la consigna que repetía y predicaba constantemente con su ejemplo, e íntegro sería la palabra elegida si tuviera que definirlo con una sola.

Se me agolpan los recuerdos, las anécdotas, las vivencias de tantos años. Desde que nos conocimos en un curso de verano de la UIMP en Santander, se estableció entre nosotros una corriente de simpatía y complicidad que nos hizo inseparables, a pesar de los muchos kilómetros que nos distanciaban. Durante ese tiempo, hemos compartido proyectos, sueños, ilusiones e incontables horas de trabajo, siempre con el buen humor como telón de fondo. Jamás tuvimos un desencuentro, ni una mala palabra, a pesar de que no siempre estuvimos de acuerdo en nuestra visión de las cosas. Pero formábamos un equipo bien avenido, sólido, complementario y siempre unido, que nos dio a los dos fortaleza y empuje.

Hoy recojo emocionada las incontables muestras de cariño que sus amigos, sus compañeros y sus alumnos han expresado a través de diferentes canales, y me siento orgullosa de su amistad, de haber formado parte de su vida y de haber aprendido a su lado. Me consuela enormemente esta marea de afecto y admiración que no es más que una pequeña muestra de todo lo bueno que él sembró a lo largo de su existencia. A todos, mi gratitud más sincera.

Querido José Luis, quedo huérfana de tu consejo y de tu apoyo, pero tu ejemplo y tu recuerdo permanecerán eternamente en mi corazón. Hasta siempre, 
querido amigo, sé que volveremos a encontrarnos.

\section{NOTA DE PRENSA}

Adiós a un maestro del protocolo, D.E.P. José Luis Delgado

Hace unos días, y coincidiendo con su cumpleaños, nos dejaba un gran maestro del protocolo, José Luis Delgado, periodista, comunicador y docente de vocación que desarrolló su actividad profesional con éxito y reconocimiento en todos los campos que fue abordando a lo largo de su vida.

Desde sus inicios periodísticos en el mítico Diario Pueblo, su amplia formación, su cultura y su capacidad innata para la comunicación le llevaron durante dos décadas a la Oficina de Información Diplomática del Ministerio de Asuntos Exteriores y, más tarde, durante catorce años a la dirección de Relaciones Institucionales de Interflora. Ya desde su propia empresa, Delgado \& Asociados, llegó al mundo de la consultoría en protocolo y comunicación, acometiendo importantes proyectos de asesoría en diversas instituciones públicas; organización y dirección de protocolo en varios congresos, actos institucionales y empresariales; intervenciones en múltiples encuentros profesionales y colaboraciones docentes en las más prestigiosas universidades. Pero también desarrolló sus propios proyectos formativos, creando en la Universidad de Salamanca los primeros cursos extraordinarios de protocolo y el primer máster centrado en esta materia, que él amaba sin paliativos.

José Luis Delgado fue un hombre carismático y pasional, entregado como pocos a su quehacer profesional, respetado y admirado por sus compañeros, y querido entrañablemente por los cientos, si no miles, de alumnos que pasaron por sus aulas.

Olga Casal Maceiras

Pequeño homenaje para José Luis Delgado.

Fui alumna suya en el postgrado de Protocolo, Comunicación e Imagen Corporativa de la Universidad de la Coruña hace un par de años. Recuerdo que su clase fue la primera de mis primeros estudios de protocolo. Recuerdo que, a pesar de que, mi intención al inscribirme en 
ese curso era estudiar el protocolo institucional, llegué tarde a su clase porque tenía un examen de mi carrera de derecho. Pero, sobre todo, recuerdo el cariño y la amabilidad con la que José Luis me trató cuando le "interrumpí" su clase. Su calidad como persona me quedó patente en los primeros momentos. Recuerdo que, a pesar de que mis expectativas eran muy altas sobre esa clase, no solo no me defraudó sino que su clase magistral se convirtió en mi favorita durante todo el curso.

También recuerdo lo amable que fue cuando me envió una solicitud de amistad en el Facebook y mi sorpresa y admiración de poder intercambiar unas palabras con él pasado ya el curso.

Pero sobre todo sobre todo, recuerdo sus palabras de aquella clase diciendo "os acordareís de mi cuando paséis delante de un edificio en el que hondeen banderas", porque es cierto, cada vez que paso por delante de ellas me paro y recuerdo aquella lección: analizo si están bien colocadas y sino, se me tuerce el gesto y me digo a mi misma, con actitud crítica, "hay que falta de profesionalidad". Esa es la palabra que me transmitía José Luis: profesionalidad. Eso debe ser el protocolo y eso, desde mi pupitre, lo aprendí de él.

Gracias por ser un referente para mí.

Que la luz brille siempre haya donde estés.

\section{Aroa FANDIÑO SERRANO}

Alumna del Postgrado en comunicación e Imagen Corporativa de la Usal.

Me encantaría tener facilidad para escribir y poder expresar mis sentimientos, pero no tengo esa virtud .

Solamente puedo manifestar la pena por esta gran pérdida de nuestro querido profesor.

Soy alumna del II postgrado de protocolo y comunicacion que se celebra en A Coruña y recuerdo como si fuera hoy mismo la primera clase del curso impartida por él, aquel entusiasmo y alegria que nos inundó a todos.

Mi más sentido pesame a todo el mundo del protocolo y a su familia y amigos mas queridos.

Atentamente

\section{Berta Gómez Tato}

Buenas tardes,

Me gustaría formar parte de aquellos que de un modo u otro quieren recordar a José Luis, al que tuve la gran suerte de conocer en la tercera edición del curso extraordinario de Protocolo en la USAL.

\section{Saludos}

Antonio Lag Camacho

La tristeza y la pena se amortiguan, en ocasiones, con el recuerdo y la admiración por una persona cercana, profesional, de esas que, a pesar de las pocas horas compartidas, dejan una profunda huella de admiración. Mis condolencias a su familia, amigos y a todos quienes le apreciábamos. José Luís, descansa en paz. En mi recuerdo siempre. Nadia Quintela (alumna Postgrado Protocolo, A Coruña 2013) 
Nadia Quintela

Periodista

Buenos días, soy exalumna del Postgrado de Protocolo de la Universidad de A Coruña, dirigido por Olga Casal y el año pasado tuve el honor de ser alumna de D. José Luis Delgado, no sé en qué formato ni cómo quieren que les pasemos los comentarios, así que les envío los comentarios que publiqué en mi muro de Facebook cuando se dio a conocer la horrible noticia de su fallecimiento.

Enhorabuena por esta iniciativa, si quieren que se lo envíe de otra forma no tienen más que decírmelo.

Un saludo,

"Esta misma semana hablaba en mi muro sobre el postgrado de Protocolo, Comunicación e Imagen Corporativa. Universidade da Coruña que cursé el año pasado, dirigido por Olga Casal. Hoy nos hemos enterado de que se ha ido uno de los mejores profesores de ese postgrado, no solo por su gran calidad como docente, sino por su cercanía y humanidad. Se ha ido una persona a la que recordaré con mucho cariño y que tendré siempre como un referente en el mundo del Protocolo. Hoy es un día muy triste. José Luis Delgado nos ha dejado. Maestro, jte tendremos siempre con nosotros!!!

"Algo muy especial tenía nuestro querido profesor cuando somos tantos los alumnos que demostramos públicamente nuestra admiración hacia su persona. Hoy mucha gente me preguntó eso de "¿lo conocías tanto?" No tiene nada que ver con eso, efectivamente no pertenecíamos a su círculo más cercano, pero me atrevo a decir que absolutamente todos los que fuimos alumnos suyos sentimos un profundo sentimiento de respeto hacia él. José Luis Delgado es de esas personas que dejan huella y que permanecerá con nosotros, siempre. Un beso a todos"

$--$

Firmas de correo.com : Luisa López Gutiérrez

Luisa López Gutiérrez

/Asesora de Comunicación/

Buenos días:

Tuve el privilegio de asistir a una clase este verano que impartía él. Nunca olvidaré la frase que nos dijo " Nunca hay una segunda oportunidad para causar la primera impresión".

¡DEP Maestro!

Un saludo,

Yolanda Fraile

Un hombre sabio y noble. Seguro que está en algún lugar celestial, presidiendo el grupo de los grandes.

Natalia Ares

Estimados amigos:

Desearía pudieran hacer llegar el siguiente mensaje a la familia de D. José

Luis Delgado, a través de la *Tabula gratulatoria* a su memoria: 
José Luis fue uno de los grandes. No sólo por su sabiduría sino por ser una persona de enorme calidad humana y elevados principios. De talante afable y bondadoso, lo consideré un buen amigo. Quizá la parca se lo llevó demasiado pronto, pero su sonrisa, su labor y su recuerdo permanecerán siempre en nuestros corazones.

José Luis, descansa en paz.

Chantal Subirats

Querido José Luis,

Siempre te llevaremos en nuestros corazones.

Un beso muy fuerte;

Dolores del Mar Sánchez

Presidenta de la Seeii 